\title{
Heat and mass transfer in laser dissimilar welding of stainless steel and nickel
}

\author{
Yaowu Hu, Xiuli He*, Gang Yu, Zhifu Ge, Caiyun Zheng, Weijian Ning \\ Key Laboratory of Mechanics in Advanced Manufacturing, Institute of Mechanics, Chinese Academy of Sciences, Beijing 100190, People's Republic of China
}

\section{A R T I C L E I N F O}

\section{Article history:}

Received 20 October 2011

Received in revised form 27 February 2012

Accepted 27 February 2012

Available online 5 March 2012

\section{PACS:}

81.20.Vj

82.20.Wt

Keywords:

Laser dissimilar welding

Heat transfer

Mass transfer

Fluid flow

\begin{abstract}
A B S T R A C T
Laser spot welding of stainless steel-nickel dissimilar couple has been studied experimentally and numerically. A three-dimensional heat and mass transfer model is used to simulate the welding process, based on the solution of the equations of mass, momentum, energy conservation and solute transport in weld pool. The calculated fusion zone geometry and element distributions are in good agreement with the corresponding experimental results. The role of fluid flow on temperature field and its evolution is analyzed by comparing two cases with and without considering convection. Temperature fields far away from the weld pool are quite similar, but exhibit large difference close to the heat source. During the early stage after formation of weld pool, the distribution of element Fe in weld pool is non-uniform, due to insufficient time for mixing. The speed for mass transport is the highest during the initial stage of weld pool formation and it decreases with time. Both heat and mass transport are significantly influenced by convection during laser spot welding of stainless steel and nickel.
\end{abstract}

(c) 2012 Elsevier B.V. All rights reserved.

\section{Introduction}

Pulsed laser spot welding is widely used for welds of small components such as microwave enclosures, batteries, and other packages which require high electrical and electronic reliability in aerospace, telecommunications, and medical industries. In recent decades, with raw-material costs on the rise, selecting a single metal for a particular product may be costly. Use of different metals and alloys in a product provides the designers and engineers with great flexibility, which often results in both technical and economic advantages over conventional manufacturing methods by using a single material. For example, a high strength stainless steel could be combined with an anti-corrosion metal such as nickel to withstand the mechanical load and chemical corrosion in high pressure containers.

However, because of the difference in physical and chemical properties of two metals, such as thermal conductivity, heat capacity, thermal expansion coefficient, and melting temperature, many problems, such as partial penetration due to insufficient heat dissipation, brittle intermetallic compound or low melting point eutectics formation due to inappropriate solute dilution or heat treatment in joining dissimilar metals, may make the joint susceptible to cracks and failures [1-5]. Choice of appropriate heat treatment temperature and composition of metal materials is an efficient way to solve these problems and obtain

\footnotetext{
* Corresponding author. Tel.: +86 10 82544251; fax: +8610 82544251 .

E-mail address: xlhe@imech.ac.cn (X. He).
}

desired microstructure and mechanical properties, which requires appropriate laser welding parameters. However, many trial experiments for these parameters appear to be time-consuming, and numerical simulation on heat and mass transfer is helpful in prediction of temperature and composition for different processing parameters.

In recent decades, computational models of heat transfer and fluid flow have been utilized to understand the evolution of temperature and velocity fields for similar metal welding applications. He et al. [6] studied the evolution of temperature and velocity fields during laser spot welding of stainless steel under the assumption of flat free surface. Marangoni-Benard convection due to temperature gradient on the surface of the molten pool and Rayleigh-Benard convection due to variation of density inside the molten pool were numerically studied and compared [7,8], under the presence or absence of surface active element such as sulfur [9-11] and oxygen [12-14]. Heat and mass losses due to vaporization of elements in conduction mode laser welding of alloys were investigated using various models [15-18]. Nonequilibrium solidification nature and solute partitioning at the solid-liquid interface in laser processing were also accounted for $[19,20]$. Most of these models basically followed fixed grid method with enthalpy-porosity formulation to deal with solid-liquid phase change problems [21-24].

Despite of the many studies on similar materials welding, only few studies addressed the modeling of dissimilar metal welding, but the interest is on the rise. Zhao and co-workers [25] used a three-dimensional FEM model to predict the temperature field under various laser powers and scanning velocities. The 


\begin{tabular}{|ll|}
\hline Nomenclature \\
$a$ & power distribution factor \\
C & specific heat \\
$C$ & species concentration \\
$D$ & species mass diffusion coefficient \\
$f$ & mass fraction \\
$g$ & volume fraction or acceleration due to gravity \\
$h_{c}$ & convective heat transfer coefficient \\
$K$ & thermal conductivity \\
$K_{0}$ & permeability coefficient \\
$k_{p}$ & partition coefficient \\
$L$ & latent heat of fusion \\
$p$ & pressure \\
$q$ & heat flux \\
$Q$ & laser power \\
$r$ & radius of laser beam \\
$S$ & source term \\
$T$ & temperature \\
$t$ & time \\
$u_{i}$ & ith component of velocity \\
Greek letters \\
$\alpha$ & thermal diffusivity \\
$\beta$ & volumetric expansion coefficient \\
$\eta$ & laser absorption efficiency \\
$\Delta H$ & latent enthalpy \\
$\varepsilon$ & emissivity \\
$\sigma_{\mathrm{b}}$ & Stefan-Boltzmann constant \\
$\rho$ & density \\
$\mu$ & dynamic viscosity \\
Subscripts \\
ref & ambient \\
c & constant \\
C & concentration \\
& liquid phase \\
\hline
\end{tabular}

simulations were then used to optimize the process parameters to control the heat input at the interface of the two metals in order to suppress the formation of brittle intermetallic compounds during laser overlap welding of Ti6Al4V and 42CrMo. Their simulation ignored the influence of Marangoni convection and mass transport. Chung and Wei [26] used a two-dimensional model to predict the shapes of fusion zones in continuous welding of two immiscible metals based on a VOF approach along with the SIMPLE algorithm. Phanikumar et al. [27,28] extended it to a three dimensional transient model to solve heat transfer, fluid flow, and species conservation during laser welding of copper-nickel dissimilar couple under the assumption of laminar fluid flow. Chakraborty and Chakraborty $[29,30]$ carried out an unsteady Reynolds Averaged Navier Stokes simulation to demonstrate the turbulent effects by comparing results under the consideration of laminar and turbulent flow.

In this work, a three-dimensional heat and mass transfer model is developed to study laser spot welding of stainless steel and nickel. Temperature field and concentration profile at different times are analyzed. The calculated weld pool dimensions and element distributions are compared with the corresponding experimental results to validate the model. This work demonstrates the application of
Table 1

Chemical composition of 304 stainless steel (atomic fraction(\%)).

\begin{tabular}{lllll}
\hline $\mathrm{Si}$ & $\mathrm{Cr}$ & $\mathrm{Mn}$ & $\mathrm{Ni}$ & $\mathrm{Fe}$ \\
\hline 0.83 & 18.43 & 1.32 & 8.45 & Bal. \\
\hline
\end{tabular}

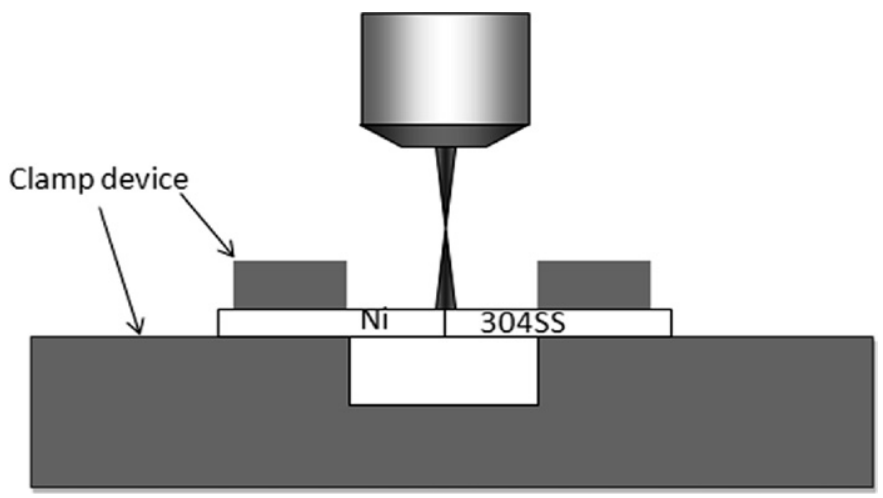

Fig. 1. Schematic representation of laser spot welding of 304 stainless steel-nickel dissimilar couple.

numerical transport phenomena can significantly add to the quantitative knowledge base in dissimilar fusion welding.

\section{Experiments}

304 stainless steel and nickel were used in the experiments. The chemical composition of 304 stainless steel is given in Table 1. The surface was cleaned with acetone before welding. Experiments were conducted on a $1 \mathrm{~kW}$ Nd:YAG laser materials processing system with five-axis CNC working station. $150 \mathrm{~mm}$ focal lens was used to focus the laser beam. The defocus distance was $9.5 \mathrm{~mm}$, and the corresponding beam radius was $1.0 \mathrm{~mm}$ at the top surface of the specimen. Laser power of $650 \mathrm{~W}$ was used and the interaction time was $500 \mathrm{~ms}$. Fig. 1 shows the schematic diagram of laser spot butt welding of 304 stainless steel and nickel sheets with the dimension of $20 \mathrm{~mm} \times 10 \mathrm{~mm} \times 2 \mathrm{~mm}$.

Metallographic samples were prepared by electric discharge cutting, mechanical milling and grinding, followed by polishing using standard mechanical polishing procedures and etching in $\mathrm{HCl}: \mathrm{HNO}_{3}$ solution with volume ratio of $3: 1$. The samples were characterized by JSM-5800 scanning electron microscopy (SEM) equipped with LinkISIS S-530 energy dispersive spectrometer (EDS).

\section{Mathematical modeling}

\subsection{Major assumptions}

In this work, a transient three-dimensional model is developed to simulate the heat and mass transfer during laser spot welding of stainless steel-nickel dissimilar couple. The following assumptions are made in order to simplify the calculations:

1. The molten metal is supposed to be Newtonian and incompressible, and the Boussinesq's approximation is used to account for the density change due to the temperature and concentration variations. The fluid flow is laminar.

2. The welding takes place in conduction mode, and the free surface of the pool is flat. Thermal contact resistance between the two work pieces is not considered.

3. The incident flux of the laser beam at the top surface of the workspace is Gaussian. 
4. Relevant physical and thermal properties of the weld pool metal, such as thermal conductivity, specific heat, and viscosity, are assumed to be temperature independent, and taken to be different for solid and liquid phase, but vary linearly with composition.

5. Binary phase diagram of the major elements is applied to study alloy solidification.

\subsection{Governing equations}

With the above assumptions, the following equations of continuity, momentum, energy and solute transport in the work piece are expressed in Eqs. (1-4).

Conservation of mass,

$\frac{\partial \rho}{\partial t}+\frac{\partial\left(\rho u_{i}\right)}{\partial x_{i}}=0$

conservation of momentum,

$\frac{\partial\left(\rho u_{i}\right)}{\partial t}+\frac{\partial\left(\rho u_{i} u_{j}\right)}{\partial x_{i}}=\frac{\partial}{\partial x_{i}}\left(\mu \frac{\partial u_{j}}{\partial x_{i}}\right)+S_{u_{i}}$

conservation of thermal energy,

$\frac{\partial(\rho c T)}{\partial t}+\frac{\partial\left(u_{i} \rho c T\right)}{\partial x_{i}}=\frac{\partial}{\partial x_{i}}\left(K \frac{\partial T}{\partial x_{i}}\right)+S_{T}$

There are mainly five elements considered, namely $\mathrm{Fe}, \mathrm{Ni}, \mathrm{Cr}, \mathrm{Si}$, and $\mathrm{Mn}$. However, as a first approximation, element Fe is thought to be representative and other elements could be calculated from its concentration. The solute transport equation for $\mathrm{Fe}$ is

$\frac{\partial(\rho C)}{\partial t}+\frac{\partial\left(\rho u_{i} C\right)}{\partial x_{i}}=\frac{\partial}{\partial x_{i}}\left(\rho D \frac{\partial C}{\partial x_{i}}\right)+S_{C}$

where the source terms are given by

$$
\begin{aligned}
S_{u_{i}=} & -\frac{\partial p}{\partial x_{i}}+\frac{\partial}{\partial x_{j}}\left(\mu \frac{\partial u_{j}}{\partial x_{i}}\right)-K_{0} \frac{\left(1-f_{\mathrm{l}}\right)^{2}}{f_{\mathrm{l}}^{3}+B} u_{i}+\rho g_{i} \beta_{\mathrm{T}}\left(T-T_{\text {ref }}\right) \\
& +\rho g_{i} \beta_{\mathrm{C}}\left(C-C_{\text {ref }}\right)
\end{aligned}
$$

$S_{T}=-\frac{\partial(\rho \Delta H)}{\partial t}-\frac{\partial\left(\rho u_{i} \Delta H\right)}{\partial x_{i}}$

$S_{\mathrm{C}}=\frac{\partial}{\partial x_{i}}\left(\rho D \frac{\partial\left(C_{1}-C\right)}{\partial x_{i}}\right)-\frac{\partial}{\partial x_{i}}\left(\rho f_{\mathrm{s}}\left(C_{1}-C_{\mathrm{s}}\right) u_{i}\right)$

The third term at the right-hand side in Eq. (5) represents the frictional dissipation of momentum in the mushy zone according to Carman-Kozeny equation for flow through porous media $[22,23,31]$. $B$ is a very small positive number introduced to avoid division by zero. The last two terms account for buoyancy effects caused by temperature and concentration variations, respectively.

In Eq. (6), $\Delta H$ is the latent enthalpy content of the computational cell under consideration given by the following expression,

$\Delta H=L f_{1}$

where the liquid mass fraction $f_{1}$ is defined as,

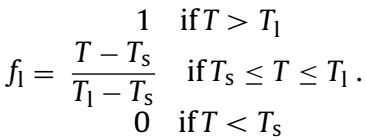

A small pseudo temperature interval between solidus and liquidus near the melting point of pure $\mathrm{Ni}$ is introduced in order to avoid divergence of calculation. Eq. (7) accounts for solute partition [31] and is calculated when solidification starts or liquid mass fraction decreases.
The nominal concentration in Eq. (4) is given by level rule,

$C=f_{\mathrm{s}} C_{\mathrm{s}}+f_{\mathrm{l}} C_{\mathrm{l}}$

at the solid-liquid interface,

$C_{\mathrm{s}}=k_{p} C_{1}$

The heat capacity, density, thermal conductivity and mass diffusion coefficient for the liquid and solid mixture are defined as follows,

$c=f_{\mathrm{s}} c_{\mathrm{s}}+f_{1} c_{1}$

$\rho=f_{\mathrm{s}} \rho_{\mathrm{s}}+f_{\mathrm{l}} \rho_{\mathrm{l}}$

$k=\left(\frac{g_{\mathrm{s}}}{k_{\mathrm{s}}}+\frac{g_{\mathrm{l}}}{k_{\mathrm{l}}}\right)^{-1}$

$D=f_{1} D_{1}$

\subsection{Boundary conditions}

At the top surface of the materials, the input heat is assumed to be distributed in a radically symmetric Gaussian manner,

$q_{\text {laser }}=\frac{a Q \eta}{\pi r_{\mathrm{b}}^{2}} \exp \left(-\frac{a\left(x^{2}+y^{2}\right)}{r_{\mathrm{b}}^{2}}\right)$

The heat loss by convection heat transfer and radiation is given by,

$q_{\text {loss }}=h_{c}\left(T-T_{\mathrm{a}}\right)+\sigma_{\mathrm{b}} \varepsilon\left(T^{4}-T_{\mathrm{a}}{ }^{4}\right)$

In the calculation, the vaporization of alloying elements is ignored, since the temperature of weld pool is below the boiling point of materials. At the top surface, the boundary condition for energy equation is given by,

$K \frac{\mathrm{d} T}{\mathrm{~d} z}=q_{\text {laser }}-q_{\text {loss }}$

Natural convection is applied to other surfaces of the specimen.

The Marangoni-driven flow at the free surface is described by,

$\mu \frac{\mathrm{d} u}{\mathrm{~d} z}=f_{1} \frac{\partial \sigma_{\text {sur }}}{\partial T} \frac{\partial T}{\partial x}+f_{\mathrm{l}} \frac{\partial \sigma_{\text {sur }}}{\partial C} \frac{\partial C}{\partial x}$

$\mu \frac{\mathrm{d} v}{\mathrm{~d} z}=f_{\mathrm{l}} \frac{\partial \sigma_{\text {sur }}}{\partial T} \frac{\partial T}{\partial y}+f_{\mathrm{l}} \frac{\partial \sigma_{\text {sur }}}{\partial C} \frac{\partial C}{\partial y}$

The two terms at the right-hand side in Eqs. (19) and (20) represent the Marangoni convection due to variations of temperature and composition, respectively.

The whole rectangular computational domain is divided into small rectangular control volumes. The governing equations are discretized using the control volume method on a staggered grid. Scalar quantities, such as pressure, temperature, species concentration, are stored at the center of the computational cell. Velocity components are stored at the corresponding cell face centers. The general framework of the numerical solution rests on the SIMPLEC algorithm [32]. A non-uniform grid of $159 \times 160 \times 50$ meshes is used, with finer grids near the heat source. The minimum grid space is $20 \mu \mathrm{m}$. The mesh grids for numerical simulation at the top surface are shown in Fig. 2. And the data used for calculations are presented in Tables 2 and 3.

\section{Results and discussion}

\subsection{Heat transport: influence of fluid flow on temperature fields}

Conventional computational welding mechanics concentrates on thermal stress and strain field, structure distortion and deformation, and the evolution of microstructure, using Fourier heat conduction model to predict the evolution of temperature field for 


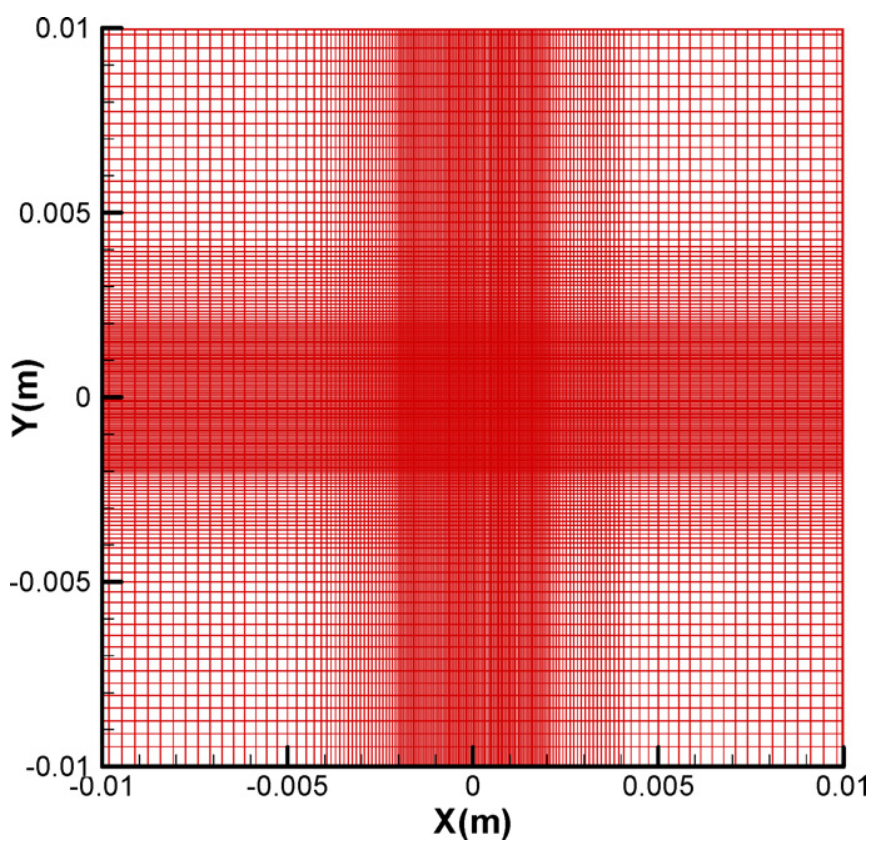

Fig. 2. Mesh grids for numerical simulation at the top surface.

the sake of simplicity [25,33]. However, during welding of dissimilar metals, fluid flow in the weld pool may have effect on heat transfer, and influence the temperature fields and species distribution. The relative importance of heat transfer by thermal convection and conduction is described by Peclet number,

$P e_{T}=R e \times P r=\frac{\rho u L_{\mathrm{R}}}{\mu} \times \frac{\mu}{\rho \alpha}$

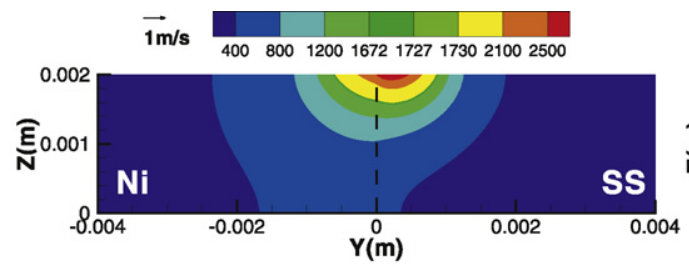

(a)

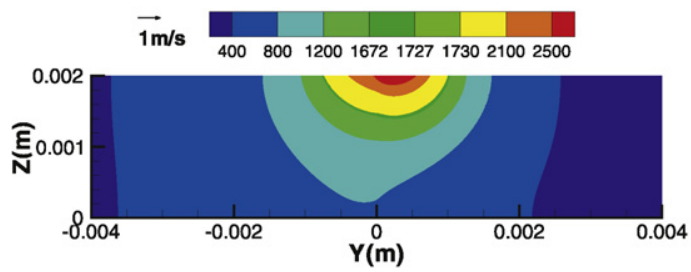

(c)

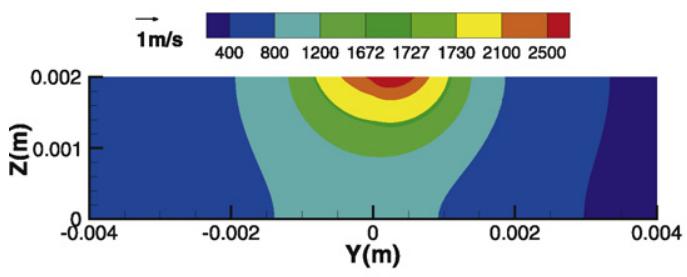

(e)
Table 2

Material properties used in the simulation [6,30,34].

\begin{tabular}{|c|c|c|}
\hline \multirow[t]{2}{*}{ Property/parameter } & \multicolumn{2}{|l|}{ Value } \\
\hline & 304SS & $\mathrm{Ni}$ \\
\hline Density of liquid metal $\left(\mathrm{kg} \mathrm{m}^{-3}\right)$ & 7200 & 8880 \\
\hline Dynamic viscosity $\left(\mathrm{kg} \mathrm{m}^{-1} \mathrm{~s}^{-1}\right)$ & $6.70 \times 10^{-3}$ & $3.68 \times 10^{-3}$ \\
\hline Solidus temperature $(\mathrm{K})$ & 1672 & 1730 \\
\hline Liquidus temperature(K) & 1727 & 1735 \\
\hline Specific heat of solid $\left(\mathrm{J} \mathrm{kg}^{-1} \mathrm{~K}^{-1}\right)$ & 711.28 & 515 \\
\hline Specific heat of liquid $\left(\mathrm{J} \mathrm{kg}^{-1} \mathrm{~K}^{-1}\right)$ & 836.8 & 595 \\
\hline $\begin{array}{l}\text { Thermal conductivity of } \\
\text { solid }\left(\mathrm{W} \mathrm{m}^{-1} \mathrm{~K}^{-1}\right)\end{array}$ & 19.2 & 60.7 \\
\hline $\begin{array}{l}\text { Effective thermal conductivity of } \\
\quad \text { liquid( }\left(\mathrm{W} \mathrm{m}^{-1} \mathrm{~K}^{-1}\right)\end{array}$ & 50 & 150 \\
\hline Surface tension $\left(\mathrm{N} \mathrm{m}^{-1}\right)$ & 1.872 & 1.778 \\
\hline $\begin{array}{l}\text { Temperature coefficient of surface } \\
\text { tension }\left(\mathrm{N} \mathrm{m}^{-1} \mathrm{~K}^{-1}\right)\end{array}$ & $-4.30 \times 10^{-4}$ & $-3.4 \times 10^{-4}$ \\
\hline Coefficient of thermal expansion $\left(\mathrm{K}^{-1}\right)$ & $1.96 \times 10^{-5}$ & $4.50 \times 10^{-5}$ \\
\hline Latent heat $\left(\mathrm{J} \mathrm{kg}^{-1}\right)$ & $2.72 \times 10^{5}$ & $2.9 \times 10^{5}$ \\
\hline Effective mass diffusivity $\left(\mathrm{m}^{2} \mathrm{~s}^{-1}\right)$ & $7 \times 10^{-7}$ & $7 \times 10^{-7}$ \\
\hline
\end{tabular}

which is on the order of $10^{2}$, thus it is expected that convection plays a vital role in heat transport.

Simulations of following two cases are performed and the results are compared to investigate the importance of fluid flow on temperature evolution.

Case 1. The effect of fluid flow is ignored. The momentum, species transport equations are not solved.

Case 2. Marangoni force, buoyancy force and thermal conduction are all considered. The influence of Marangoni convection on the weld pool configuration, temperature field is analyzed.

Fig. 3(a-f) shows the comparison of the two cases on computed temperature and velocity fields at various times during the heating period. The contour values in figures represent the temperature in

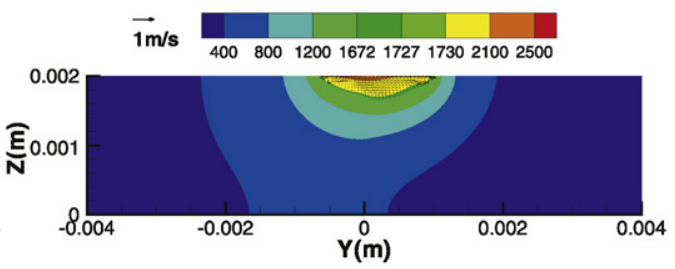

(b)

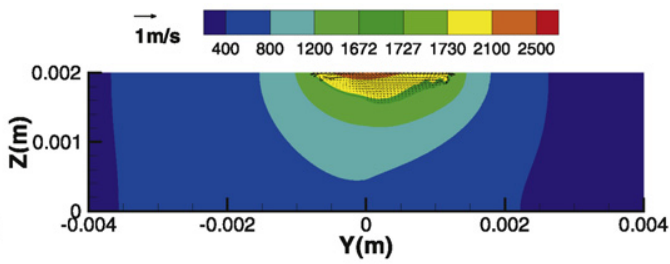

(d)

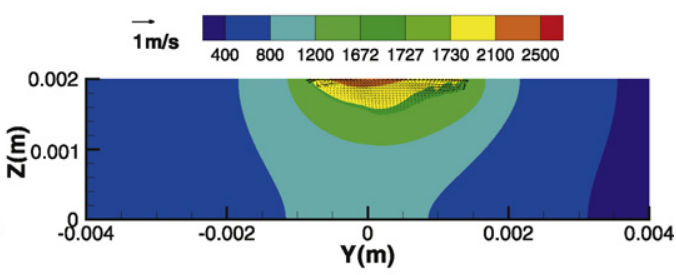

(f)

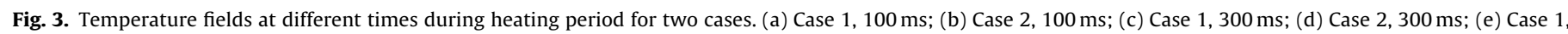
$500 \mathrm{~ms}$ and (f) Case 2, $500 \mathrm{~ms}$. (For interpretation of the references to color in this figure legend, the reader is referred to the web version of the article). 


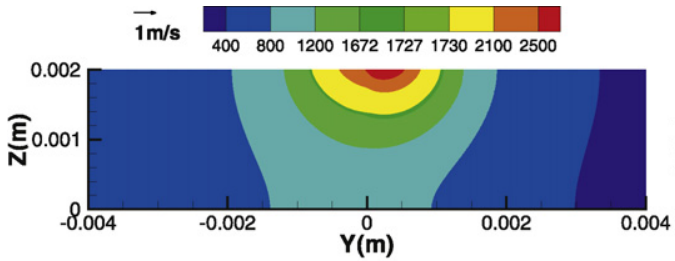

(a)

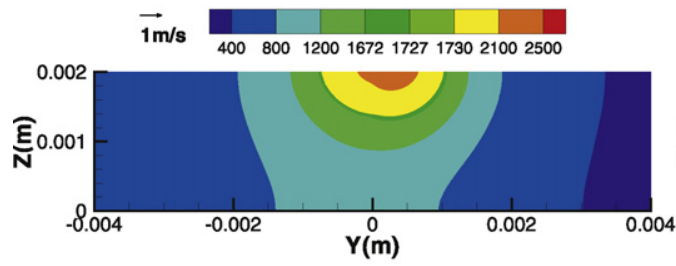

(c)

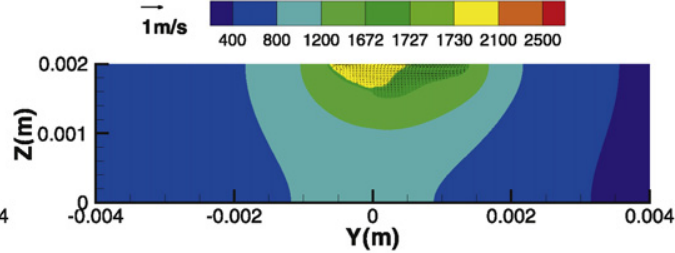

(b)

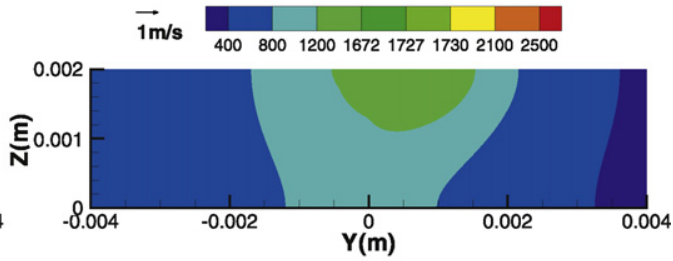

(d)

Fig. 4. Temperature fields at different times during cooling period for two cases. (a) Case 1, 5 ms; (b) Case 2, 5 ms; (c) Case 1, 30 ms and (d) Case 2, 30 ms.

Kelvin. The yellow and red parts represent the liquid region. It can be seen that temperature fields far away from the weld pool are similar at various times for the two cases, showing some reasonableness of ignoring fluid flow and mass transport in traditional welding mechanics. However, it is quite different for the region close to the heat source. For Case 1, the fusion zone is deeper and narrower, and has a hemispheric shape, resulting from energy being radially transported from the center of the laser beam by heat conduction alone. The peak temperatures are always at the 304 stainless steel side, since its thermal conductivity is much less than nickel. For Case 2, when fluid flow and mass transport are taken into consideration, the peak temperatures shift towards the center of the laser beam due to the maximum heat input flux. With the negative temperature coefficients of surface tension, the fluid flows from the center of the laser beam, where surface tension becomes smaller, towards the periphery of the weld pool, enhancing energy transport from the hot parts to the cool parts. As a result, the peak temperature for Case 2 is much lower than that for Case 1 ( $2423 \mathrm{Kvs.}$ $3058 \mathrm{~K}$ ), and the temperature gradients in the weld pool are smaller during the heating period. Fig. 4(a-d) shows the comparisons of the two cases on computed temperature and velocity fields during the cooling cycle. The weld pool for Case 2 stays in liquid state for only $30 \mathrm{~ms}$ after the laser is switched off, while the time for Case 1 is much longer (about $140 \mathrm{~ms}$ ).

The temperature gradients are of vital importance in thermal stress generation, and the temperature itself influences the stressstrain relationship. Depending on the ratio of the local temperature and the melting temperature, the constitutive model assigned may vary from being rate independent plasticity (less than 0.5 ), rate dependent plasticity (0.5-0.8), to linear viscous (above 0.8) [33]. Thus the evolution of both temperature and temperature gradients should be investigated. Fig. 5 shows the temperature evolution of

Table 3

Data used for calculations [35].

\begin{tabular}{lc}
\hline Parameter & Value \\
\hline Power distribution factor & 2 \\
Laser absorption efficiency & 0.5 \\
Convective heat transfer coefficient at & 100 \\
$\quad$ top surface $\left(\mathrm{W} \mathrm{m}^{-2} \mathrm{~K}^{-1}\right)$ & \\
Ambient temperature $(\mathrm{K})$ & 298 \\
Emissivity & 0.2 \\
Stefan-Boltzmann constant & $5.67 \times 10^{-8}$ \\
$\quad\left(\mathrm{~W} \mathrm{~m} \mathrm{~K}^{-2}\right)$ & \\
\hline
\end{tabular}

two locations $0.5 \mathrm{~mm}$ away from the heat source. As shown in figure, when temperatures exceed the solidus, the cooling rate is much higher for Case 2. This could be attributed to the fluid flow, which serves as another mechanism to transport heat from the hot parts to the cool parts besides heat conduction, making the hot parts get cooled down more quickly.

The evolution of temperature difference between the two locations for two cases is also different. During heating period, the temperature difference between the two locations for Case 2 is much less than that for Case 1 , because of fluid flow serving to enhance heat transport from hot parts to cool parts. After the laser is switched off, weld pool solidifies and fluid flow weakens and disappears quickly. The primary mechanism of heat transport is thermal conduction, and the temperature at the nickel side decreases more quickly than that at the stainless steel side, since nickel has a higher thermal conductivity. As a result, for Case 2 , the temperature difference between the two locations increases, compared with that during heating period, the case is a little different for Case 1. Even though the thermal conductivity of stainless steel is lower, the high temperature gradient caused during heating period results in a comparable heat flux, leading to small temperature difference between the two locations during cooling period.

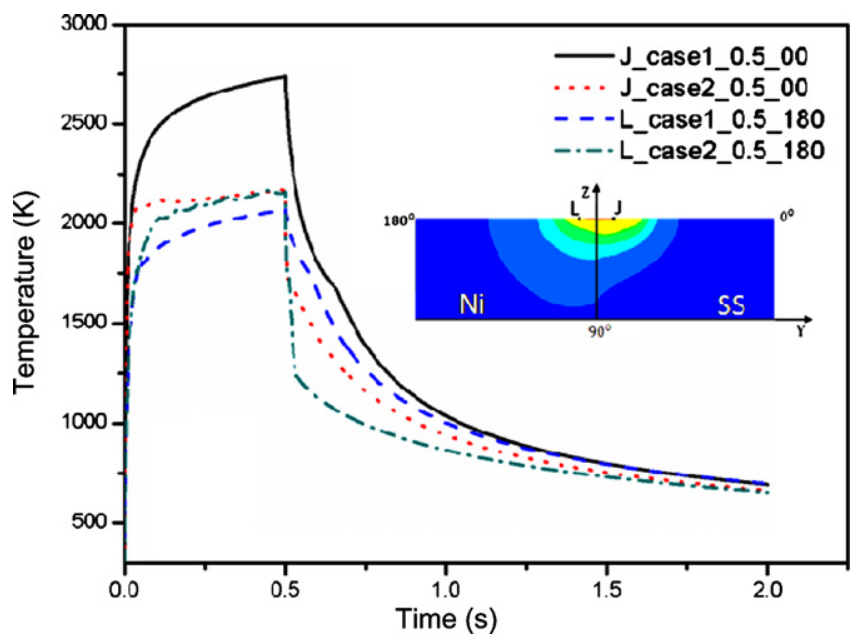

Fig. 5. Weld thermal cycles at different locations. 


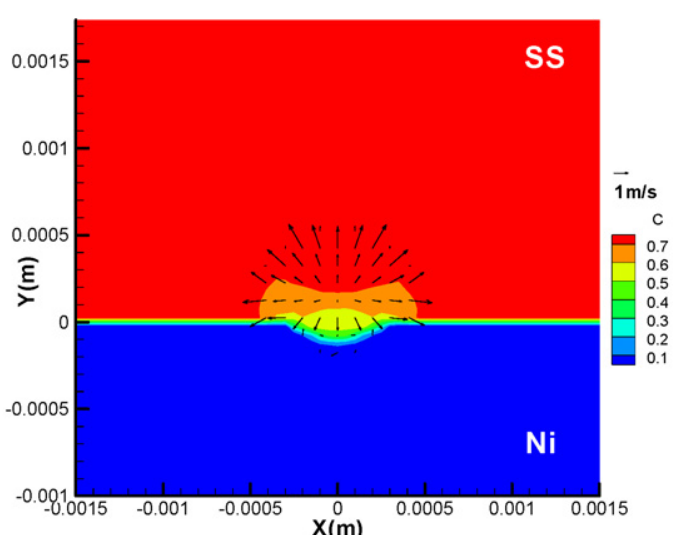

(a)

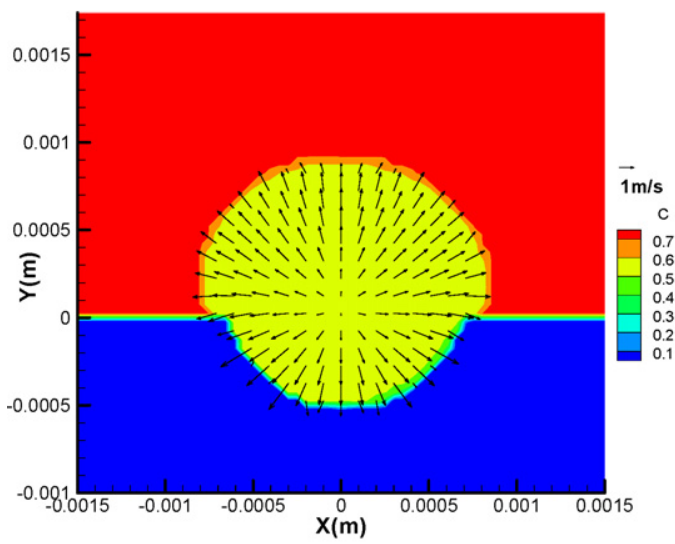

(c)

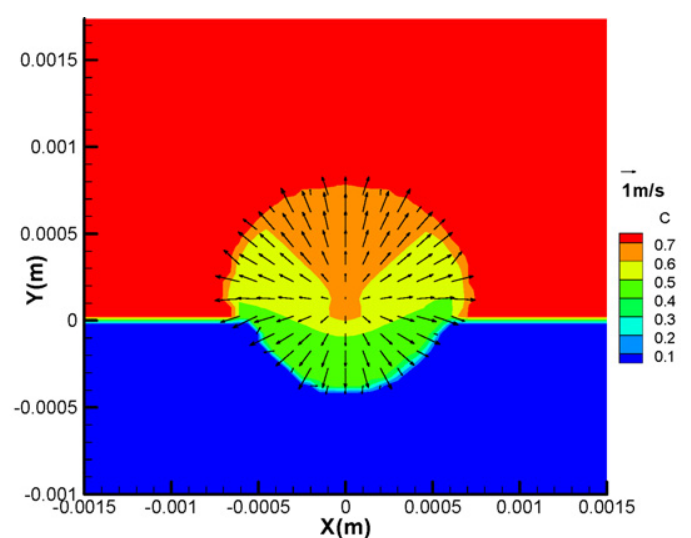

(b)

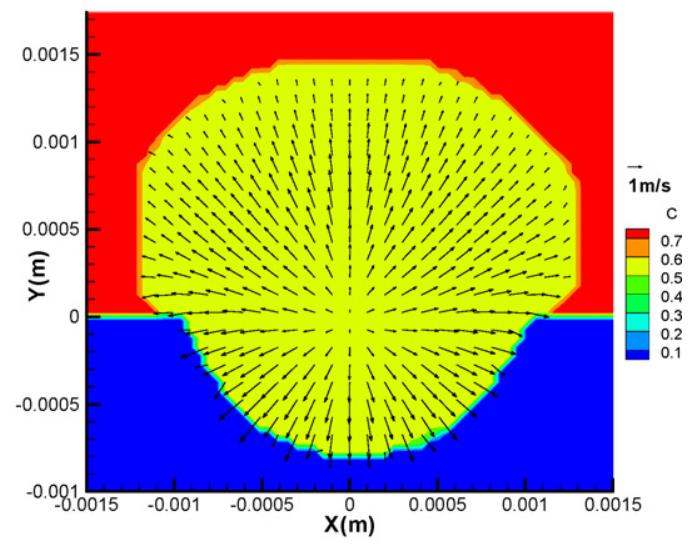

(d)

Fig. 6. Concentration profile of Fe at the top surface for different times of (a) $10 \mathrm{~ms}$; (b) $30 \mathrm{~ms}$; (c) $60 \mathrm{~ms}$ and (d) $500 \mathrm{~ms}$.

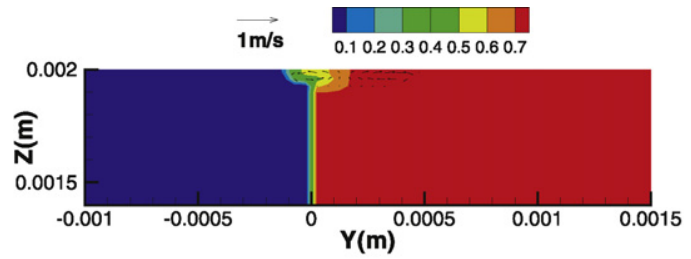

(a)

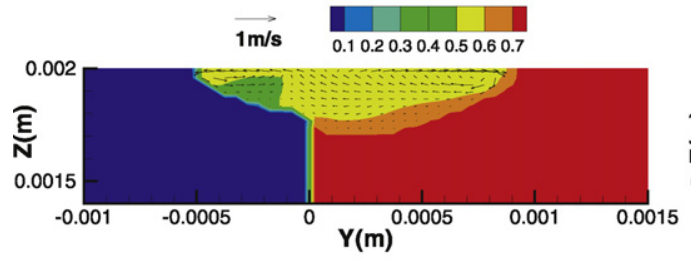

(c)

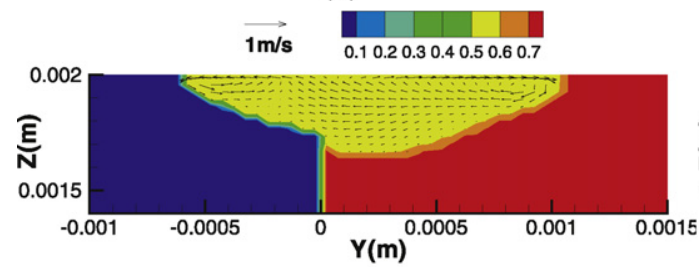

(e)

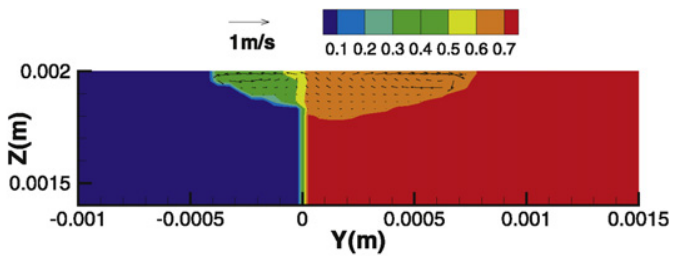

(b)

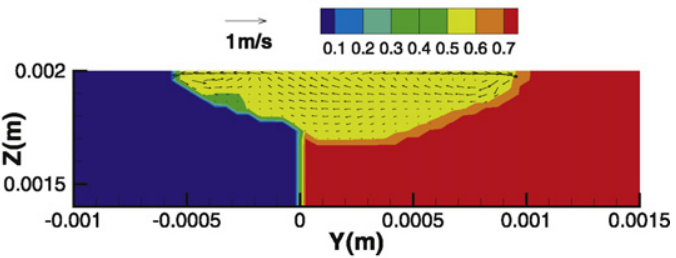

(d)

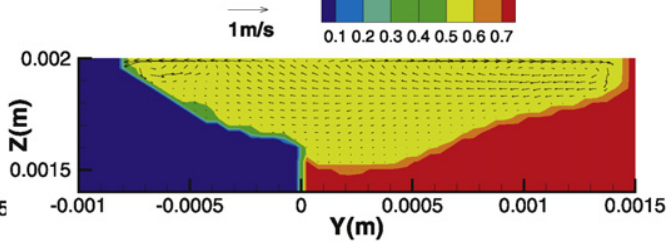

(f)

Fig. 7. Concentration profile of Fe along the cross section for different times of (a) $10 \mathrm{~ms}$; (b) $30 \mathrm{~ms}$; (c) $60 \mathrm{~ms}$; (d) $90 \mathrm{~ms}$; (e) $120 \mathrm{~ms}$ and (f) $500 \mathrm{~ms}$. 


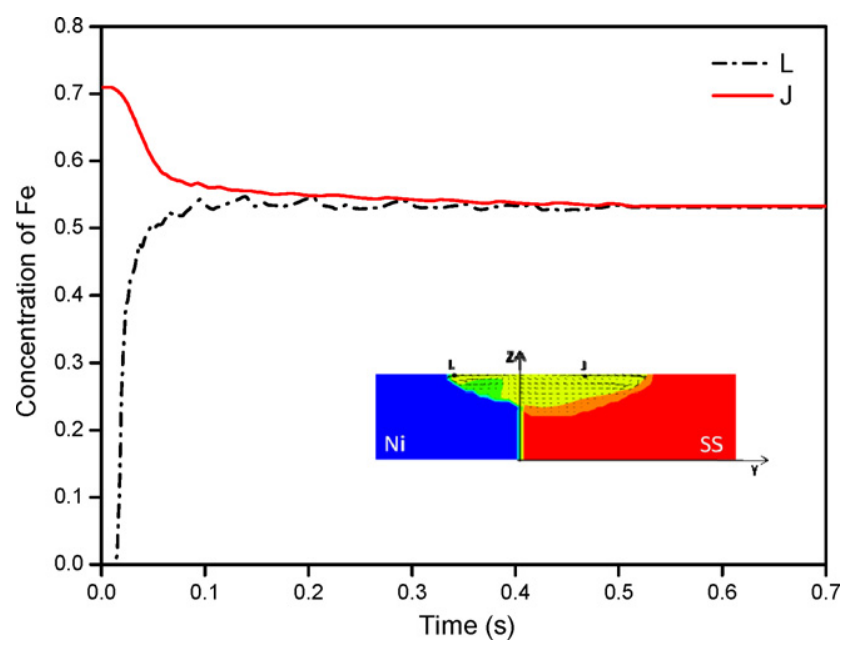

Fig. 8. Concentration evolution of Fe at different locations.

\subsection{Transport of mass}

Mass transport is based on two mechanisms, namely fluid flow and mass diffusion. The dimensionless number to describe the relative importance of these two mechanisms is given by,

$P e_{\mathrm{C}}=\frac{u L_{\mathrm{R}}}{D}$

which is on the order of $10^{3}$ or $10^{4}$, so the mass distribution in welding of dissimilar couple is greatly influenced by fluid flow, and, to a much lesser extent, by mass diffusion.

When the weld pool begins to form, the fluid flow transports the element, such as $\mathrm{Fe}$ and $\mathrm{Cr}$, from stainless steel side to the nickel side, and these elements are mixed with nickel. Similarly, nickel element is transported from nickel side to the stainless steel side. The concentration profile of Fe at the top surface and the cross section for different times is shown in Figs. 6 and 7, respectively. For the top surface, the distribution of element Fe in weld pool is non-uniform during the first $60 \mathrm{~ms}$, due to insufficient time for mixing. After $60 \mathrm{~ms}$, metals of both sides continue melting and the dimension of weld pool continues enlarging, with a nearly uniform concentration distribution at the top surface. However, for the cross section, the Fe element is not uniformly distributed at $60 \mathrm{~ms}$, especially near the solid/liquid interface. The time for uniformly distribution of Fe element for the cross section is longer, approximately $90 \mathrm{~ms}$. Therefore, the mass transfer is more quickly at top surface than cross section. The convection on the top surface is strong, due to the Marangoni stresses, caused by both temperature gradient and concentration gradient. A non-uniform element distribution would result in large Marangoni stress, which in turn would accelerate fluid flow to transport mass.

Fig. 8 shows the concentration evolution of Fe for the two locations $0.5 \mathrm{~mm}$ away from the heat source. As shown in figure, after the formation of melt pool, the elements mix quickly. As a result, the concentration of Fe decreases at the stainless steel side while increases at the nickel side during the initial stage of melting, with a high speed. As the concentration difference of the two locations decreases, the mass transport becomes more slowly. Therefore, both the concentration difference of the two locations and the speed for mass transport decrease with time until the element distribution becomes uniform during laser spot welding of stainless steel and nickel.

For laser welding, a uniform solute distribution is desired, since the non-uniform distribution of alloying elements may seriously affect mechanical performance of the weldment. The uniformity of

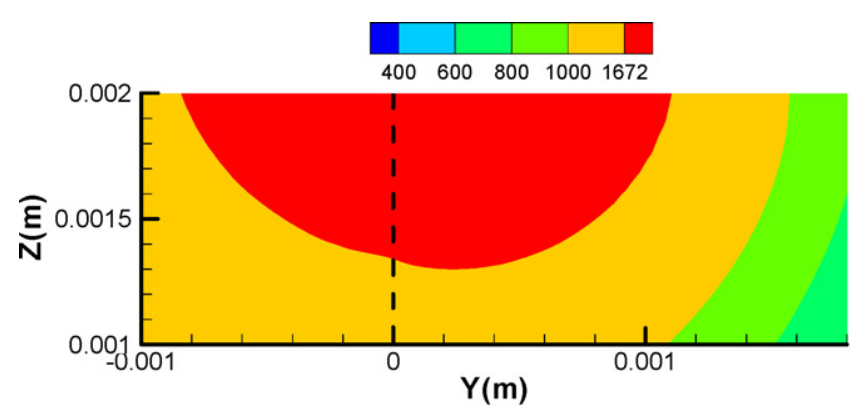

(a)

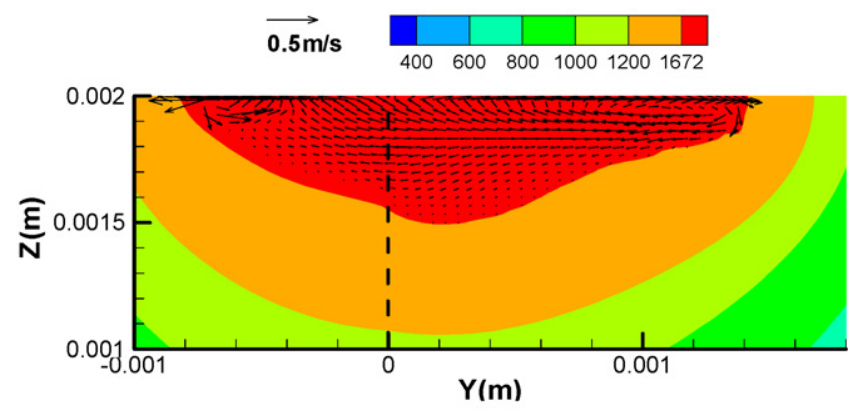

(b)

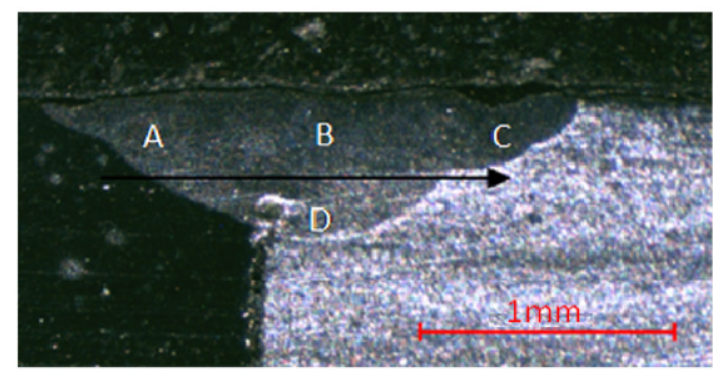

(c)

Fig. 9. Experimental and calculated weld pool cross sections (a) simulated for Case 1; (b) simulated for Case 2 and (c) from experiments.

mixing and the resultant concentration distribution are primarily determined by convection in the weld pool. The numerical model is helpful in predicting the composition profile to seek optimum laser welding parameters necessary for an appropriate microstructure and target mechanical properties.

\subsection{Comparison between calculated and experimental results}

The experimentally determined weld pool cross section is compared with the corresponding computed result in Fig. 9. It is observed that the calculated weld pool geometry and dimensions for Case 2 agree better with the experimental results, while the fusion zone for Case 1 is much deeper and narrower. The dimension of the fusion zone at the nickel side is smaller than the radius of laser beam $(1.00 \mathrm{~mm})$, because of the high conductivity of solid nickel. On the contrary, the fusion zone $(1.4 \mathrm{~mm})$ at the stainless steel side is much larger, and its dimension exceeds the radius of laser beam.

Fig. 10 shows the comparison of calculated and experimental element distributions. The scan track is shown in Fig. 9(c). The atomic fractions of element Fe for points A, B, C and D are compared in Table 4 . The calculated results are in good agreements with the experimental results, showing the validity of the numerical model presented in this paper. Elements are almost uniformly distributed in the weld pool by Marangoni convection and mass diffusion, and 

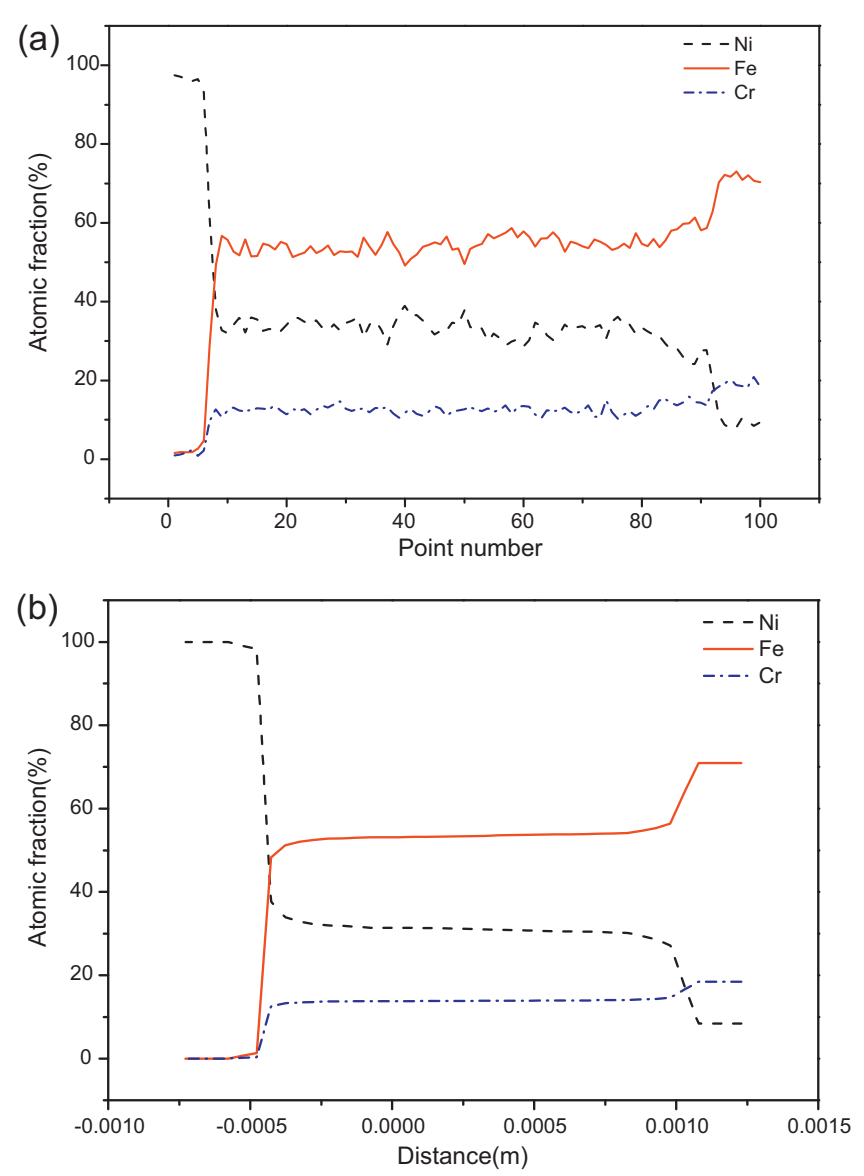

Fig. 10. Experimental (a) and calculated (b) element distribution.

Table 4

Experimental and calculated atomic fraction of Fe element for various locations (\%).

\begin{tabular}{lllll}
\hline & A & B & C & D \\
\hline Experimental & 52.3 & 52.8 & 53.5 & 51.8 \\
Calculated & 52.4 & 53.2 & 53.7 & 53.6 \\
\hline
\end{tabular}

solute partition during solidification is not obvious according to Fe-Ni binary phase diagram.

It is worth noting that Marangoni stress due to concentration gradient always tends to make the elements uniformly distributed, since the potential energy of it is the lowest under this equilibrium condition. However, it does not necessarily mean that element distribution should be uniform during any laser processing. Other factors, such as insufficient time for mixing because of short pulse duration or fast scanning speed, or solute redistribution during rapid solidification, which cannot be ignored when non-equilibrium partition coefficient $\left(k_{p}\right)$ is far away from unity, would result in non-uniform distribution. Other complex issues such as porosity, keyhole formation and surface tension variation because of active elements in the alloys, also play important parts in heat and mass transport in laser welding of dissimilar metals, and provide challenges for future study.

\section{Conclusions}

The heat and mass transfer during laser spot welding of stainless steel-nickel dissimilar couple has been studied using a 3D transient numerical model. The calculated fusion zone geometry and element distribution agree well with the experimental results. Some of the important findings from the investigation are as follows:

(1) Simulation results of two cases are presented to illustrate the importance of fluid flow on heat transport during laser welding of dissimilar couple. The temperature fields far away from the weld pool are not influenced by the presence of fluid flow. However, for the location close to the heat source, when fluid flow is taken into consideration, both peak temperature and temperature gradient decrease during heating period. The cooling rate increases, and the weld pool solidifies more quickly.

(2) The distribution of element Fe in weld pool is uniform after $90 \mathrm{~ms}$, because of sufficient time for mixing. Mass transport is more quickly at the top surface than cross section due to the strong convection. The speed of mass transport is the highest during the initial stage of weld pool formation and it decreases with time during laser spot welding of stainless steel and nickel.

\section{Acknowledgment}

The research was sponsored by National Natural Science of China (grant no.10972222 and 10832011).

\section{References}

[1] H.C. Chen, A.J. Pinkerton, L. Li, Fibre laser welding of dissimilar alloys of Ti-6Al$4 \mathrm{~V}$ and Inconel 718 for aerospace applications, Int. J. Adv. Manuf. Technol. 52 (2011) 977-987.

[2] Z. Sun, J.C. Ion, Laser-welding of dissimilar metal combinations, J. Mater. Sci. 30 (1995) 4205-4214.

[3] C.W. Yao, B.S. Xu, X.C. Zhang, J. Huang, J. Fu, Y.X. Wu, Interface microstructure and mechanical properties of laser welding copper-steel dissimilar joint, Opt. Lasers Eng. 47 (2009) 807-814.

[4] A. Mathieu, R. Shabadi, A. Deschamps, M. Suery, S. Mattei, D. Grevey, E. Cicala, Dissimilar material joining using laser (aluminum to steel using zinc-based filler wire), Opt. Lasers Technol. 39 (2007) 652-661.

[5] S. Chakraborty, S. Mukherjee, R. Galun, Y. Estrin, I. Manna, Transport phenomena in conduction mode laser beam welding of Fe-Al dissimilar couple with Ta diffusion barrier, Int. J. Heat Mass Transfer 53 (2010) 5274-5282.

[6] X. He, P.W. Fuerschbach, T. DebRoy, Heat transfer and fluid flow during laser spot welding of 304 stainless steel, J. Phys. D: Appl. Phys. 36 (2003) 1388-1398.

[7] A. Kumar, S. Roy, Effect of three-dimensional melt pool convection on process characteristics during laser cladding, Comp. Mater. Sci. 46 (2009) 495-506.

[8] S.Z. Shuja, B.S. Yilbas, Laser produced melt pool: Influence of laser intensity parameter on flow field in melt pool, Opt. Lasers Technol. 43 (2011) 767-775.

[9] T. Zacharia, S.A. David, J.M. Vitek, T. Debroy, Weld pool development during Gta and laser-beam welding of type-304 stainless-steel. 1. Theoretical-analysis, Weld. J. 68 (1989) S499-S509.

[10] T. Zacharia, S.A. David, J.M. Vitek, T. Debroy, Weld pool development during Gta and laser-beam welding of type-304 stainless-steel. 2. Experimental correlation, Weld. J. 68 (1989) S510-S520.

[11] S. Mishra, T.J. Lienert, M.Q. Johnson, T. DebRoy, An experimental and theoretical study of gas tungsten arc welding of stainless steel plates with different sulfur concentrations, Acta Mater. 56 (2008) 2133-2146.

[12] Y.Z.Zhao, Y.W. Shi, Y.P. Lei, The study of surface-active element oxygen on flow patterns and penetration in A-TIG welding, Metall. Mater. Trans. B 37 (2006) 485-493.

[13] Y.Z.Zhao, H.P. Zhou, Y.W. Shi, The study of surface active element on weld pool development in A-TIG welding, Model. Simul. Mater. Sci. 14 (2006) 331-349.

[14] C.X.Zhao, C. Kwakernaak, Y. Pan, I.M. Richardson, Z. Saldi, S. Kenjeres, C.R. Kleijn, The effect of oxygen on transitional Marangoni flow in laser spot welding, Acta Mater. 58 (2010) 6345-6357.

[15] Y.P. Lei, H. Murakawa, Y.W. Shi, X.Y. Li, Numerical analysis of the competitive influence of Marangoni flow and evaporation on heat surface temperature and molten pool shape in laser surface remelting, Comp. Mater. Sci. 21 (2001) 276-290.

[16] X. He, T. DebRoy, P.W. Fuerschbach, Alloying element vaporization during laser spot welding of stainless steel, J. Phys. D: Appl. Phys. 36 (2003) 3079-3088.

[17] K. Mundra, T. Debroy, Calculation of weld metal composition change in highpower conduction mode carbon-dioxide laser-welded stainless-steels, Metall. Trans. B 24 (1993) 145-155.

[18] H. Zhao, T. Debroy, Weld metal composition change during conduction mode laser welding of aluminum alloy 5182, Metall. Mater. Trans. B32 (2001) 163-172.

[19] S. Mishra, S. Chakraborty, T. DebRoy, Probing liquation cracking and solidification through modeling of momentum, heat, and solute transport during welding of aluminum alloys, J. Appl. Phys. 97 (2005). 
[20] S. Chakraborty, P. Dutta, Numerical modeling of heat and mass transfer in laser surface alloying: non-equilibrium solidification effects, Mater. Manuf. Processes 17 (2002) 455-468.

[21] A.D. Brent, V.R. Voller, K.J. Reid, Enthalpy-porosity technique for modeling convection-diffusion phase-change - application to the melting of a pure metal, Numer. Heat Transfer 13 (1988) 297-318.

[22] W.D. Bennon, F.P. Incropera, A continnum model for momentum, heat and species transport in binary solid liquid-phase change systems -I. Model formulation, Int. J. Heat Mass Transfer 30 (1987) 2160-2170.

[23] W.D. Bennon, F.P. Incropera, A continnum model for momentum, heat and species transport in binary solid liquid-phase change systems-II. Application to solidification in a rectangular cavity, Int. J. Heat Mass Transfer 30 (1987) 2171-2187.

[24] V.R. Voller, C. Prakash, A fixed grid numerical modeling methodology for convection diffusion mushy region phase-change problems, Int. J. Heat Mass Transfer 30 (1987) 1709-1719.

[25] G. Yu, S.S. Zhao, X.L. He, Y.J. Zhang, W.J. Ning, Numerical simulation and experimental investigation of laser overlap welding of Ti6Al4V and 42CrMo, J. Mater. Process. Technol. 211 (2011) 530-537.

[26] F.K. Chung, P.S. Wei, Mass momentum, and energy transport in a molten pool when welding dissimilar metals, J. Heat Transfer-T ASME 121 (1999) 451-461.
[27] G. Phanikumar, K. Chattopadhyay, P. Dutta, Modelling of transport phenomena in laser welding of dissimilar metals, Int. J. Numer. Method. H 11 (2001) 156-171.

[28] G. Phanikumar, P. Dutta, K. Chattopadhyay, Computational modeling of laser welding of Cu-Ni dissimilar couple, Metall. Mater. Trans. B35 (2004) 339-350.

[29] N. Chakraborty, S. Chakraborty, Modelling of turbulent molten pool convection in laser welding of a copper-nickel dissimilar couple, Int. J. Heat Mass Transfer 50 (2007) 1805-1822.

[30] N. Chakraborty, The effects of turbulence on molten pool transport during melting and solidification processes in continuous conduction mode laser welding of copper-nickel dissimilar couple, Appl. Therm. Eng. 29 (2009) 3618-3631.

[31] V.R. Voller, A.D. Brent, C. Prakash, The modeling of heat, mass and solute transport in solidification systems, Int. J. Heat Mass Transfer 32 (1989) 1719-1731.

[32] S.V.Patankar, Numerical Heat Transfer and Fluid Flow, McGraw-Hill, New York 1980.

[33] J.A. Goldak, M. Akhlaghi, Computational Welding Mechanics, Springer, New York, 2005.

[34] A. Nayar, The Metals Databook, McGraw-Hill, New York, 1997.

[35] P.W. Fuerschbach, G.R. Eisler, Effect of laser spot weld energy and duration on melting and absorption, Sci. Technol. Weld. Joining 7 (2002) 241-246. 